\title{
Rapid and Safe Correction of Vitamin B12 Deficiency using Novel Methylcobalamin Nasal Spray
}

\author{
Tulika Seth ${ }^{1}$, Vikas Suri², Dushyant Balat ${ }^{3}$, Sachin Murthy ${ }^{4}$, Ajay Agarwal ${ }^{5}$, Prabu Pandurangan $^{6}$, Prantar Chakrabarti $^{7}$, \\ Arun Maseeh ${ }^{8, *}$, and Ketan R Patel ${ }^{8}$
}

\author{
${ }^{1}$ Department of Hematology, All India Institute of Medical Sciences (AlIMS), New Delhi, India \\ ${ }^{2}$ Department of Internal Medicine, Post-Graduate Institute of Medical Education \& Research (PGIMER) Chandigarh, India \\ ${ }^{3}$ Department of Internal Medicine, Apollo Hospitals International Ltd., Gandhinagar, India \\ ${ }^{4}$ Department of Medicine, Sapthagiri Institute of Medical Sciences \& Research Center, Bangalore, India \\ ${ }^{5}$ Department of Internal Medicine, Fortis Hospital, Noida, India \\ ${ }^{6}$ Department of Hematology, Apollo Hospitals, Chennai, India \\ ${ }^{7}$ Nil Ratan Sircar (NRS) Medical College and Hospital, Kolkata, India \\ ${ }^{8}$ Troikaa Pharmaceuticals Limited, Bodakdev, Ahmedabad, India
}

*Corresponding author: Dr. Arun Maseeh, Medical Department, Troikaa Pharmaceuticals Limited, Bodakdev, Ahmedabad, India 380054, Tel: +917926856242; E-mail: arunmaseeh@troikaapharma.com

Received: 05 Jan, 2021 | Accepted: 22 Jan, 2021 | Published: 29 Jan, 2021

Citation: Seth T, Suri V, Balat D, Murthy S, Agarwal A, et al. (2021) Rapid and Safe Correction of Vitamin B12 Deficiency using Novel Methylcobalamin Nasal Spray. Int J Endocrinol Metab Disord 7(1): dx.doi.org/10.16966/2380-548X.172

Copyright: (C) 2021 Seth T, et al. This is an open-access article distributed under the terms of the Creative Commons Attribution License, which permits unrestricted use, distribution, and reproduction in any medium, provided the original author and source are credited.

\section{Abstract}

Background \& Aims: Methylcobalamin nasal spray (NasoB12 $)$ has been developed to overcome the drawbacks of currently available therapeutic options like the poorly absorbed oral route and the painful intramuscular route. The present study was designed to evaluate the safety and efficacy of NasoB12 ${ }^{\circ}$ in patients with Vitamin B12 deficiency, with serum vitamin B12 (svB12) <200 pg/mL (148 pmol/L).

Methods: This prospective, multicentric, open-label, clinical study was conducted in 103 vitamin B12-deficient patients (58 men, 45 women; 18-55 years). In the treatment phase of interventions, 7 doses of NasoB $12^{\circ} 500 \mathrm{mcg} /$ dose on alternate days for 2 weeks were given. Patients with Vitamin $\mathrm{B} 12>200 \mathrm{pg} / \mathrm{mL}$ (148 pmol/L) after two weeks of treatment received maintenance therapy with weekly NasoB12 $500 \mathrm{mcg} / \mathrm{dose}$ for 4 weeks. Primary outcome was the proportion of patients with svB12 levels $>200 \mathrm{pg} / \mathrm{ml}$ after $2^{\text {nd }}$ and $6^{\text {th }}$ weeks. Secondary outcomes included svB12 levels and blood hemoglobin.

Results: After $2^{\text {nd }}$ and $6^{\text {th }}$ weeks of treatment, $100 \%(81 / 81)$ and $95.06 \%(77 / 81)$ of patients achieved svB12 levels $>200 \mathrm{pg} / \mathrm{mL}(148 \mathrm{pmol} / \mathrm{L})$ respectively. Mean svB12 levels increased significantly from $123.10 \mathrm{pg} / \mathrm{mL}$ (baseline) to $530.07,718.69,627.76$ and $676.70 \mathrm{pg} / \mathrm{mL}$ after $1^{\text {st }}, 2^{\text {nd }}, 4^{\text {th }}$ and $6^{\text {th }}$ weeks respectively.

Hemoglobin significantly increased from $11.94 \mathrm{~g} / \mathrm{dL}$ (baseline) to $12.39,12.76,13.25$ and $13.58 \mathrm{~g} / \mathrm{dL}$ after the $1^{\text {st }}, 2^{\text {nd }}, 4^{\text {th }}$ and $6^{\text {th }}$ weeks respectively. Reticulocyte count, demonstrated trend consistent with erythpoietic activity: a borderline higher value at $1^{\text {st }}$ and $2^{\text {nd }}$ weeks; and once hemoglobin approached $12.76 \mathrm{~g} / \mathrm{dL}$, the reticulocyte count started normalizing; but the hemoglobin kept rising till normal.

No serious/severe treatment-emergent adverse events were reported.

Conclusion: NasoB12 is well-tolerated and rapidly corrects vitamin B12 deficiency with a rise in hemoglobin. NasoB $12^{\circ}$ offers a favorable alternative to oral/intramuscular B12 formulations.

Clinical Trial Registry: CTRI No.: CTRI/2015/06/005952 at www.ctri.nic.in.

Keywords: Methylcobalamin; Nasal spray; Vitamin B12 Deficiency; Novel Drug Delivery System Hemoglobin; Anemia

\section{Introduction}

Vitamin B12 (B12, also known as cobalamin) is a B vitamin that has an important role in cellular metabolism, especially in DNA synthesis, methylation and mitochondrial metabolism [1]. Serum vitamin B12 (svB12) levels, that are low $(<150 \mathrm{pg} / \mathrm{mL})$ or low-normal (150-399 pg/
$\mathrm{mL}$ ) [2] may lead to hematologic, neurologic, gastrointestinal, and vascular consequences [3].

Vitamin B12 deficiency has a global incidence of 5\%-60\% [4]. Plasma Vitamin B12 concentrations were assessed cross-sectionally for 2999 subjects in the general population of the Framingham 
Offspring Study: 39\% had serum vitamin B12 levels <258 Pmol/L $(<350 \mathrm{pg} / \mathrm{mL})[5,6]$. A large $(\mathrm{n}=176,702)$ neonatal and maternal study demonstrated the advantages of identifying and correcting B12 deficiency [7].

The administration of $\mathrm{B} 12$ by the nasal route has a 70 -year history, starting from nasal drops used for treating patients suffering from pernicious anemia [8] to cyanocobalamin nasal spray in the recent decades. Considering the potential advantages offered by a nasal spray over oral/injectable routes, and of methylcobalamin over other forms, a novel methylcobalamin nasal spray has been recently developed and received regulatory approval (Troikaa Pharmaceuticals Limited). In a first-in-human randomized, single-dose, two-way crossover comparative bioavailability study conducted at a CRO for global regulatory approvals, it was found that the relative bioavailability of NasoB $12^{\circ}$ was $20 \%$ that of intramuscular methylcobalamin (Clinical Trial Registry: CTRI/2015/04/005687). In this study we have evaluated the safety and efficacy of NasoB12 ${ }^{\circ}$ in patient with Vitamin B12 deficiency (svB12 $<200 \mathrm{pg} / \mathrm{mL}(148 \mathrm{pmol} / \mathrm{L}))$.

\section{Material and Methods}

This prospective, multicentric, open-label, clinical study was conducted in accordance with declaration of Helsinki (59 $9^{\text {th }}$ WMA General Assembly, Seoul, October 2008); Schedule Y (amended version, 2005) of CDSCO, India; Ethical Guidelines for Biomedical Research on Human Participants, ICMR (2006); and ICH, E6Guideline for GCP. Enrollment for this clinical trial began in late 2015, and ended in late 2018. The trial was conducted at 7 urban tertiary care centers. Electrochemiluminescence immunoassay (ECLIA) and Spectophotometry methods were used to determine serum vitamin B12 and hemoglobin respectively.

The trial protocol and informed consent form were reviewed, approved, monitored and overseen by a duly constituted Independent Ethics Committee (IEC) at each site. Informed consent was obtained from each patient. The contract research organization, QED clinical services private limited, was responsible for data management, statistical analysis, clinical study report writing. Full details of the trial design, conduct, oversight, and analyses can be found in the protocol and statistical analysis plan.

\section{Patients}

193 consecutive asymptomatic adults aged 18-72 years, who gave written informed consent were screened for vitamin B12 deficiency at 7 tertiary hospitals. Out of these 103 patients ( 58 men, 45 women) with $\mathrm{svB} 12<200 \mathrm{pg} / \mathrm{mL}(148 \mathrm{pmol} / \mathrm{L})$ when screened were included. Individuals with known hypersensitivity or cobalt allergy or any background illness were excluded. (More details about Protocol INMEC CT/31/01/12 are available on the Clinical Trial Registry: CTRI/2015/06/005952).

\section{Treatment}

NasoB12 ${ }^{\circ}$ (Methylcobalamin $250 \mathrm{mcg} / 0.05 \mathrm{~mL} /$ actuation) was administered as 1 actuation per nostril, i.e. 2 actuations $/ 500 \mathrm{mcg}$ dose. Patients were treated with $500 \mathrm{mcg}$ intranasal methylcobalamin total 2 actuations at a time on alternate days for 2 weeks ( 7 doses) in treatment phase and with $500 \mathrm{mcg}$ intranasal methylcobalamin, once in a week for 4 weeks ( 4 doses) in maintenance phase. Total 11 doses of the study drug were given to the patient during the study. Since all forms of Vitamin B12 are destroyed by light, precautions were taken to prevent photodegradation included the use of amber coloured USP type I glass vial as primary pack and specially coated outer-cartons as a secondary pack to protect the formulation from light.

\section{Sample size}

Assuming an overall success rate of $75 \%$ at treatment phase and $85 \%$ at maintenance phase compared to null hypothesis of $60 \%$ success rate, at least 32 efficacy evaluable subjects were required to complete the study. By assuming 40\% drop out at treatment phase and 25\% dropout at maintenance phase, 72 subjects were required to achieve $90 \%$ power with $5 \%$ level of significance. [Software: PASS (Power Analysis and Sample size) version 11]. However, as per local regulatory recommendations, 100 patients were to be enrolled in this study.

\section{Efficacy analysis}

For efficacy assessment, primary efficacy endpoint was evaluated as the proportion of patients achieving svB12 levels $>200 \mathrm{pg} / \mathrm{mL}(148$ $\mathrm{pmol} / \mathrm{L}$ ) after the $2^{\text {nd }}$ and $6^{\text {th }}$ week. The secondary endpoints included svB12 and hemoglobin levels after the $1^{\text {st }}, 2^{\text {nd }}, 4^{\text {th }}, 6^{\text {th }}$ weeks of treatment. Further the Physician's Global Assessment of Efficacy was assessed as secondary end point. Efficacy assessment was done on Per Protocol Population (PP) which consisted of the subjects who completed the study in compliance with the protocol and had no major protocol violations that impacted the efficacy assessments.

\section{Safety analysis}

Incidence/severity of Treatment-Emergent Adverse Events (TEAEs), abnormality in vital signs/physical examination, and global tolerability were included in safety assessment. Safety analyses were performed on safety population where all subjects who received at least one dose of the study medication were included. Summary statistics were presented as numbers and percentages of patients experiencing treatment emergent adverse events.

\section{Statistical analysis}

In general, continuous data was presented by descriptive statistics i.e. $n$, mean, standard deviation, median, minimum and maximum values. Categorical data was presented as frequency (n) and percentage. Visit 1 (Day-7 to 0) was considered as the Baseline visit.

The statistical analysis was done in accordance with the ICH-E9 guidelines "Statistical Principles for Clinical Trials" and guidelines from CDSCO and USFDA guideline and applicable regulatory guidelines. All reports outputs were produced using SAS ${ }^{\star}$ version 9.4 in a secure and validated environment. (Statistical analysis plan, version 1.0:27NOV2017)

\section{Results}

\section{Patient enrollment}

A total of 193 patients were screened, and 103 were enrolled (Figure 1).

Eligibility was based on the Vitamin B12<200 pg/mL (148 pmol/L) \& Folate levels $>3 \mathrm{ng} / \mathrm{mL}$.

81 patients $(78.6 \%)$ completed the study and were included in the efficacy analysis (Per Protocol Population). Total 103 patients were evaluated for safety analysis.

\section{Demographics and other baseline characteristics and outcome}

The mean age of the patient was 38.45 years with BMI of $23.83 \mathrm{~kg} / \mathrm{m}^{2}$. There were $56.3 \%$ of male and $43.7 \%$ were of female patients (Table $1 \mathrm{~A}$ ). 


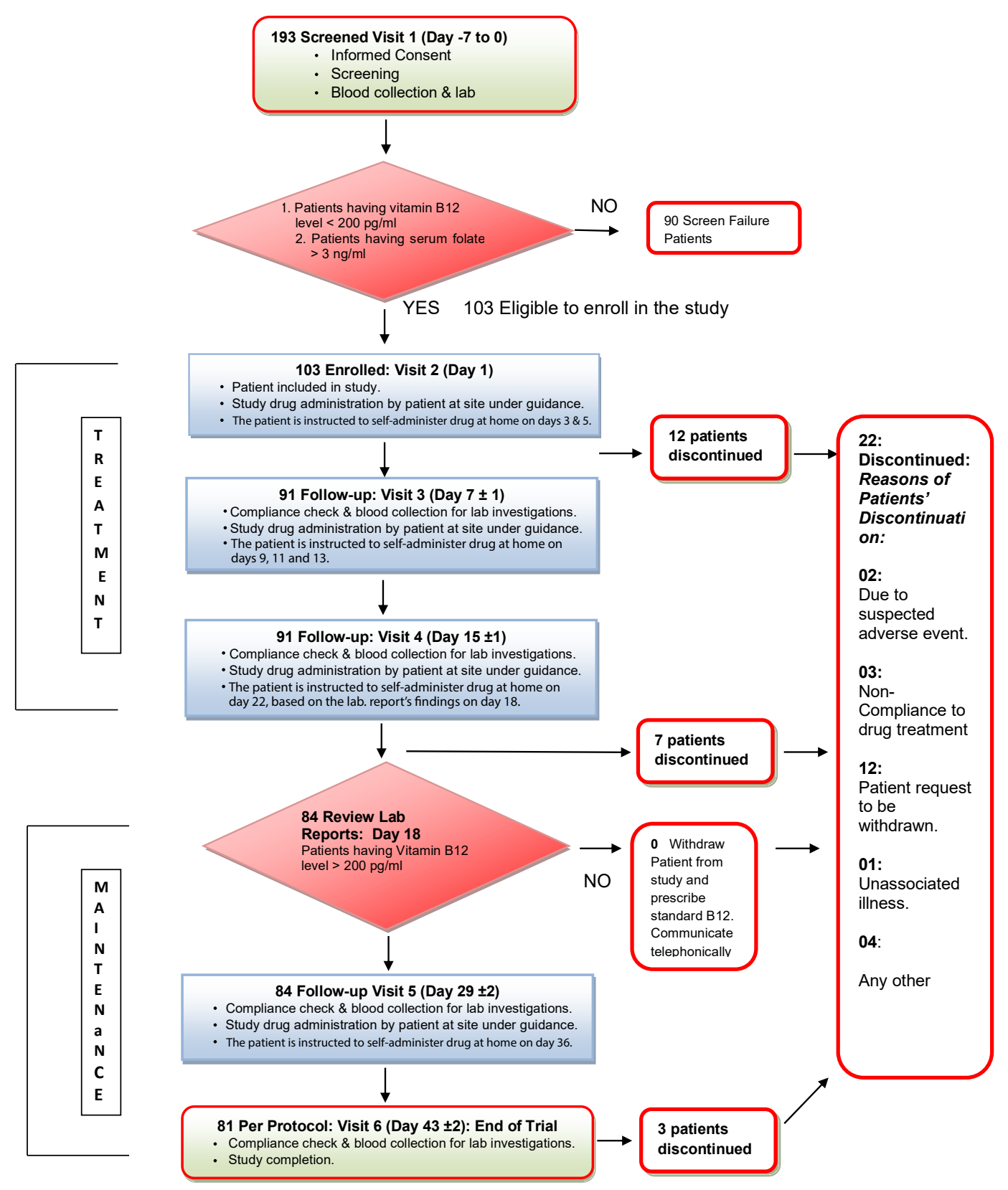

Figure 1: Flow diagram for patient screened, selected and included in the study.

\section{Primary efficacy endpoints}

$100 \%(81 / 81)$ and $95.06 \%(77 / 81)$ patients had $\mathrm{B} 12>200 \mathrm{pg} / \mathrm{mL}$ $(148 \mathrm{pmol} / \mathrm{L})$ after the $2^{\text {nd }}$ and $6^{\text {th }}$ weeks respectively $(\mathrm{p}<0.0001)$ (Table 1B, Figure 2).

\section{Secondary efficacy endpoints}

Vitamin B12 levels: Statistically significant changes in B12 levels $(\mathrm{pg} / \mathrm{mL})$ were observed from 123.98 at Baseline, to 530.07 and 718.69 after the $1^{\text {st }}$ and $2^{\text {nd }}$ week respectively ("Treatment Phase") (both $\mathrm{p}<0.0001$ ) and $676.70 \mathrm{pg} / \mathrm{mL}$ after the $6^{\text {th }}$ week ("Maintenance Phase") ( $\mathrm{p}<0.001$ [Student't' test]) (Figure 2).

A transient statistically significant change was observed in B12 levels after the $4^{\text {th }}$ week as compared to the $2^{\text {nd }}$ week, which was considered clinically acceptable considering the reduction in dosing frequency from alternate-day to once-weekly dosing. (Change at $4^{\text {th }}$ and $6^{\text {th }}$ weeks were: $-90.93 \mathrm{pg} / \mathrm{mL} ;(\mathrm{p}=0.027)$ and $-41.99 \mathrm{pg} / \mathrm{mL}$ ( $p=0.683$ ) respectively. Thus, by the end of the $6^{\text {th }}$ week, the decrease in B12 level was insignificant as compared to $2^{\text {nd }}$ week. The significant aspect of weekly therapy is that mean B12 levels were maintained well above $400 \mathrm{pg} / \mathrm{mL}$.

Hemoglobin levels: Hemoglobin increased rapidly after the $1^{\text {st }}$, $2^{\text {nd }}, 4^{\text {th }}$, and $6^{\text {th }}$ weeks: from Baseline 11.94 to $12.39,12.76,13.25$ and $13.58 \mathrm{~g} / \mathrm{dL}$ respectively ( $\mathrm{p}$ versus baseline $<0.0001$ [from Binomial Exact test]). The change in hemoglobin versus baseline after the $1^{\text {st }}, 2^{\text {nd }}$, $4^{\text {th }}$, and $6^{\text {th }}$ weeks was: $0.45,0.82,1.31$ and $1.64 \mathrm{~g} / \mathrm{dL}$ respectively $(\mathrm{p}=$ 0.0002 at week $1 ; \mathrm{p}<0.0001$ at weeks 2,4 and 6) (Figure 2). 
Table 1A: Demographic characteristics of study participants and baseline data $(\mathrm{N}=103)$

\begin{tabular}{|c|c|}
\hline \multicolumn{2}{|c|}{ Characteristics } \\
\hline \multicolumn{2}{|l|}{ Age (Years) } \\
\hline Mean & 38.45 \\
\hline Min, $\max$ & 18,72 \\
\hline Males: Mean & 39.44 \\
\hline Males: Min, max & 18,72 \\
\hline Females: Mean & 37.15 \\
\hline Females: Min, max & 18,55 \\
\hline \multicolumn{2}{|l|}{ Gender, n (\%) } \\
\hline Male & $58(56.3)$ \\
\hline Female & $45(43.7)$ \\
\hline \multicolumn{2}{|l|}{ BMI $\left(\mathrm{kg} / \mathrm{m}^{2}\right)$} \\
\hline Mean & 23.83 \\
\hline Min, max & $13.5,37.8$ \\
\hline Males: Mean & 24.04 \\
\hline Males: Min, max & $14.5,32.3$ \\
\hline Females: Mean & 23.54 \\
\hline Females: Min, max & $13.5,37.8$ \\
\hline \multicolumn{2}{|c|}{ Serum vitamin B12 levels pg/ml : Baseline } \\
\hline Mean & 123.1 \\
\hline Min, $\max$ & $13.75,570$ \\
\hline Males: Mean & 124.13 \\
\hline Males: Min, max & $48.3,570$ \\
\hline Females: Mean & 123.76 \\
\hline Females: Min, max & 13.75, 197 \\
\hline \multicolumn{2}{|c|}{ Hb levels g/dL : Baseline } \\
\hline Mean & 11.94 \\
\hline Min, max & $6.2,16.5$ \\
\hline Males: Mean & 12.62 \\
\hline Males: Min, max & $6.2,16.5$ \\
\hline Females: Mean & 11.03 \\
\hline Females: Min, $\max$ & $7.7,13.6$ \\
\hline
\end{tabular}

A review of 'Prior and Concomitant Medication' confirmed that only $3.7 \%$ (3/81) patients received iron (Ferrous Sulfate) $200 \mathrm{mg} /$ day $(\mathrm{n}=2 / 81)$ or $400 \mathrm{mg} /$ day $(\mathrm{n}=1 / 81)$ for iron deficiency and all completed the study. An analysis of the $96.3 \%$ (78/81) subjects not receiving iron showed similar outcomes to the overall ("composite") population (Appendix: Supplementary Figure SF1).

Hemoglobin levels progressively increased from baseline hemoglobin of 11.92 to $12.39,12.79,13.28$ and $13.63 \mathrm{~g} / \mathrm{dL}$ after the $1^{\text {st }}, 2^{\text {nd }}, 4^{\text {th }}$, and $6^{\text {th }}$ weeks respectively. In other words, the rise of hemoglobin was seen irrespective of iron supplementation. Reticulocyte count, demonstrated trend consistent with erythpoietic activity: a borderline higher value at $1^{\text {st }}$ and $2^{\text {nd }}$ weeks; and once hemoglobin approached $12.76 \mathrm{~g} / \mathrm{dL}$, the reticulocyte count started normalizing; but the hemoglobin kept rising till normal (Appendix: Supplementary Figure SF2).

Physician's global assessment of efficacy: Physicians rated the treatment efficacy as "excellent" or "good" for $98.7 \%$ of patients $(58 \%$ and $40.7 \%$, respectively) (Figure 3 ).

\section{Safety analysis}

NasoB $12^{\circ}$ was well-tolerated. The most common adverse events were gastrointestinal, metabolism and nutrition disorders (3.9\% $[n=4]$ patients each). No deaths/ serious/ severe TEAEs were reported. Overall 14\% patients reported 26 events of which 11 were considered treatment-related. One patient experienced a mild non-serious TEAE (nasal congestion) which resolved without any treatment being required (Table 2 and 3 ).

The physicians' global assessment of tolerability: Except for 1 patient, the investigators rated the global tolerability as "excellent" (no adverse event reported) or "good" (mild adverse event; resolved spontaneously; no stoppage of treatment) for all patients in the study (86.4\% [n=76] and $12.5 \%[\mathrm{n}=11]$ patients, respectively).

\section{Discussion}

These are the results of the first prospective, multi-centric, clinical study to evaluate the safety and efficacy of NasoB $12^{\circ}$ in treatment and maintenance therapy of B12 deficiency. The American Academy of Family Physicians (2017) [2] stratified patients into the following groups:

"Low" (svB12 <150 pg/mL i.e. Classical deficiency),

"Low Normal" (svB12 150-399 pg/mL i.e. Subclinical Cobalamin Deficiency (SCCD1,)) and

"Normal" (i.e. svB12 $400 \mathrm{pg} / \mathrm{mL}$ and above) [9].

The SCCD concept was not well established when this study was designed and hence the protocol used the cut-off of svB12<200 pg/ $\mathrm{mL}(148 \mathrm{pmol} / \mathrm{L})$ which was prevailing at that point of time (in 2015). Current scientific consensus (e.g. AAFP) targets the svB12>296 $\mathrm{pmol} / \mathrm{l}$ (400 pg/ml and above) as normal levels; [10] hence we would like to utilize this perspective while discussing our results.

Our study did not target symptomatic adults, but included all types of individuals with low B12 levels, because researchers today believe in the existence of a wide spectrum of patients with no symptoms to mild to severe manifestations which could be neuropsychiatric (e.g. neuropathic pain; cognitive impairment), hematologic (megaloblastic anemia; pancytopenia), obstetric (Neural Tube Defects; growthretardation) and pediatric (cognitive; anemia) [2,11-14].

A positive outcome was achieved during the study, as $100 \%$ and $95 \%$ of patients achieved the primary efficacy endpoint of B12>200 $\mathrm{pg} / \mathrm{mL}(148 \mathrm{pmol} / \mathrm{L})$ after the $2^{\text {nd }}$ and $6^{\text {th }}$ week respectively.

From the very first week of $\mathrm{NasoB} 12^{\circ}$ therapy, the svB12 levels crossed well above $400 \mathrm{pg} / \mathrm{mL}$, into the "normal range" [2]. Subsequently normal svB12 levels were maintained at all time-points, including the $500 \mathrm{mcg}$ once-weekly maintenance therapy. This makes NasoB $12^{\circ}$ an attractive alternative for both: the treatment as well as the maintenance therapy of B12 deficient patients.

The mean Hemoglobin of B12 deficient patients consistently increased each week from baseline hemoglobin of $11.94 \mathrm{~g} / \mathrm{dL}$ to 13.58 $\mathrm{g} / \mathrm{dL}$ at the end of the study (Figure 2), and where only $3.7 \%$ patients received a concomitant iron supplementation. Our study corroborates the concept that a rapid rise in B12 levels is associated with a rise in hemoglobin. Andrès E, et al. [13] previously demonstrated this trend in hematological outcomes in 10 patients with B12 malabsorption and cobalamin deficiency treated over 3 months. In contrast, administration of $\mathrm{NasoB} 12^{\circ}$ in the current work gave the rise in Hemoglobin $(0.45 \mathrm{~g} / \mathrm{dL}, \mathrm{p}=0.0002)$ as early as the $1^{\text {st }}$ week and this trend was sustained till the $6^{\text {th }}$ week, when normal hemoglobin levels were attained (corresponding to a rise of $1.64 \mathrm{~g} / \mathrm{dL}, \mathrm{p}<0.0001$ ). 
Table 1B: Outcomes by gender $(\mathrm{N}=103)$.

\begin{tabular}{|c|c|c|c|}
\hline $\begin{array}{l}\text { Proportion of patients with serum vitamin B12 levels }>200 \mathrm{pg} / \mathrm{mL}(148 \mathrm{pmol} / \mathrm{L}) \\
\text { at the end of the } 2^{\text {nd }} \text { week; } \%(\mathrm{n}=)\end{array}$ & $100 \%(n=81)$ & \multicolumn{2}{|c|}{ Hemoglobin levels g/dL: end of week 1} \\
\hline Overall Proportion \% and (n) & $100 \%(n=81 / 81$ & Mean & 12.39 \\
\hline Males Proportion \% and (n) & $100 \%(n=46 / 46)$ & Min, $\max$ & $8.2,16.5$ \\
\hline Females Proportion \% and (n) & $100 \%(n=35 / 35)$ & Males: Mean & 13.03 \\
\hline $\begin{array}{l}\text { Proportion of patients with serum vitamin B12 levels }>200 \mathrm{pg} / \mathrm{mL}(148 \mathrm{pmol} / \mathrm{L}) \\
\text { at the end of the } 6^{\text {th }} \text { week; } \%(\mathrm{n}=)\end{array}$ & $95.06 \%(n=77 / 81)$ & Males: Min, max & $8.2,16.5$ \\
\hline Overall Proportion \% and (n) & $95.06 \%(n=77 / 81)$ & Females: Mean & 11.54 \\
\hline Males Proportion \% and (n) & $95.6 \%(n=44 / 46)$ & Females: Min, $\max$ & $8.3,13.9$ \\
\hline Females Proportion \% and (n) & $94.28 \%(n=33 / 35)$ & \multicolumn{2}{|c|}{ Hemoglobin levels g/dL: end of week 2} \\
\hline Serum vitamin B12 levels pg/ml : end of week 1 & & Mean & 12.76 \\
\hline Mean & 530.07 & Min, $\max$ & $8.7,16.8$ \\
\hline Min, $\max$ & $133.9,>2000$ & Males: Mean & 13.36 \\
\hline Males: Mean & 589.5 & Males: Min, $\max$ & $8.7,16.8$ \\
\hline Males: Min, max & $154.9,2000$ & Females: Mean & 11.97 \\
\hline Females: Mean & 451.9 & Females: Min, $\max$ & $8.9,13.6$ \\
\hline Females: Min, $\max$ & $133.9,>2000$ & \multicolumn{2}{|c|}{ Hemoglobin levels g/dL: end of week 4} \\
\hline Serum vitamin B12 levels pg/ml : end of week 2 & & Mean & 13.25 \\
\hline Mean & 718.69 & Min, $\max$ & $10,16.5$ \\
\hline Min, $\max$ & $206.8,2106$ & Males: Mean & 13.81 \\
\hline Males: Mean & 720.4 & Males: Min, max & $10,16.5$ \\
\hline Males: Min, $\max$ & $206.8,2000$ & Females: Mean & 12.49 \\
\hline Females: Mean & 716.4 & Females: Min, max & $10.2,14.6$ \\
\hline Females: Min, $\max$ & 208,2106 & $\begin{array}{l}\text { Hemoglobin levels g/dL: } \\
\text { end of week } 6\end{array}$ & \\
\hline Serum vitamin B12 levels pg/ml : end of week 4 & & Mean & 13.58 \\
\hline Mean & 627.76 & Min, $\max$ & $8.7,17.2$ \\
\hline Min, $\max$ & $219.5,2000$ & Males: Mean & 14.16 \\
\hline Males: Mean & 603.4 & Males: Min, $\max$ & $11.3,17.2$ \\
\hline Males: Min, $\max$ & $219.5,2000$ & Females: Mean & 12.81 \\
\hline Females: Mean & 659.7 & Females: Min, max & $8.7,15.2$ \\
\hline Females: Min, $\max$ & $257.5,1871$ & & \\
\hline \multicolumn{2}{|l|}{ Serum vitamin B12 levels pg/ml : end of week 6} & & \\
\hline Mean & 676.7 & & \\
\hline Min, $\max$ & $100.5,7200$ & & \\
\hline Males: Mean & 781 & & \\
\hline Males: Min, $\max$ & 169,7200 & & \\
\hline Females: Mean & 539.5 & & \\
\hline Females: Min, max & $100.5,1380$ & & \\
\hline
\end{tabular}

Irrespective of the baseline iron stores, the baseline hemoglobin values were similar and patients experienced a consistent weekly rise in Hemoglobin, both in the treatment phase (alternate-day NasoB12) as well as in the maintenance phase (once-weekly NasoB12).

In our trial $4.9 \%(\mathrm{n}=4)$ patients did not experience a rise in B12 levels. This appears modest compared to $33 \%(\mathrm{n}=17 / 51)$ non-responders reported, after patients received hydroxocobalamin nasal drops for 3 months [14]. The authors suggested that the non-responders had either low B12 protein saturation or a very rapid urinary excretion. In this study the authors used 5,000 mcg one nasal drop in each nostril, twice per week, [14] while the current work employs the scheme with administration of a smaller dose i.e. $500 \mathrm{mcg}$ every alternate day for seven doses, followed by weekly dosing. Small but frequent doses of B12 are known to be more efficient for upload of B12 into the tissues, compared to large but rare doses because low doses do not overload the specific transport system of B12 (in intestine and blood). Excessive vitamin $\mathrm{B} 12$ in the circulation, e.g., such as after injections, usually exceeds the binding capacity of specific protein, (Transcobalamin) 


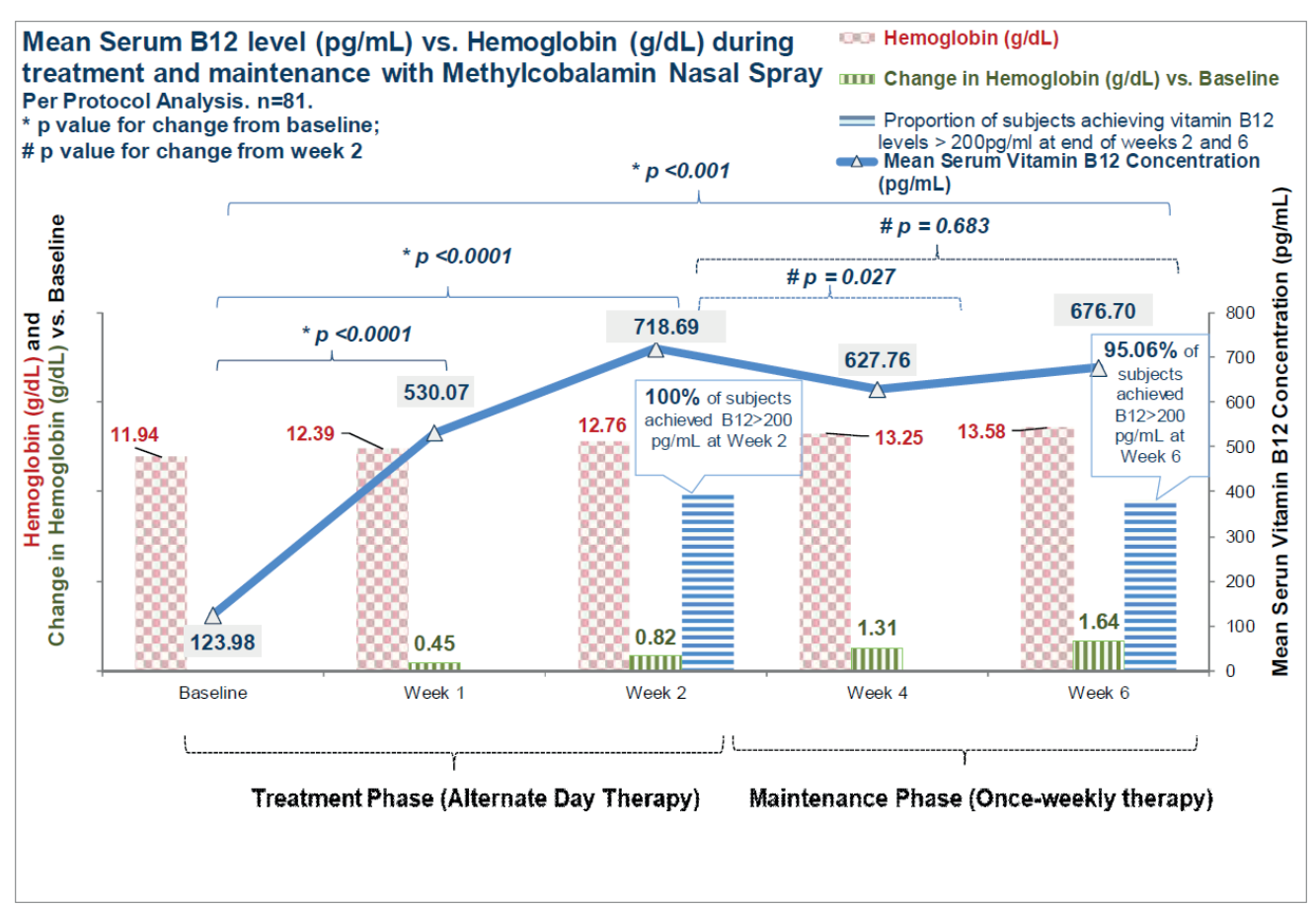

Figure 2: Mean Serum B12 level $(\mathrm{pg} / \mathrm{mL})$ vs. Hemoglobin $(\mathrm{g} / \mathrm{dL})$ during treatment and maintenance with Methylcobalamin nasal spray: Per Protocol Analysis. $\mathrm{n}=81$. Secondary efficacy endpoints.

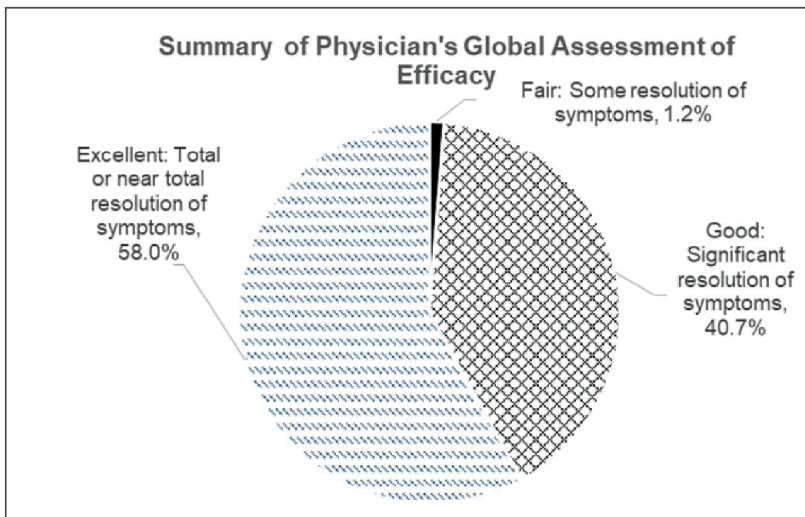

Figure 3: Physician's global assessment of efficacy.

Table 2: Overall summary of treatment-emergent adverse events (Safety Population; Total $n=103$ ).

\begin{tabular}{|l|c|}
\hline \multicolumn{1}{|c|}{ Patient Category } & $\mathbf{n}(\%)$ \\
\hline Number of events & 26 \\
\hline Number of treatment-related events & $11 / 26$ (42.3\%) \\
\hline Number of patient(s): & $14 / 103$ (13.6\%) \\
\hline With at least one event & 0 \\
\hline With at least one severe event & 0 \\
\hline With at least one serious event & $5 / 103$ (4.9\%) \\
\hline With at least one treatment-related event & $\begin{array}{l}\text { Note: Treatment-related Adverse Events are events with relationship } \\
\text { indicated as: 'Certain' or 'probable' or 'possible' or 'missing'. }\end{array}$ \\
\hline
\end{tabular}

and is excreted in the urine [1]. NasoB $12^{\circ}$ was found to be safe, well tolerated and no serious adverse events were reported..

\section{The limitations of other approaches}

It is now known that there are at least four forms of vitamin B12 (cobalamin), i.e. cyanocobalamin, hydroxocobalamin and two coenzymes forms which are biochemically active, namely methylcobalamin and adenosylo-cobalamin [1,15-17].

Nasal formulations using Cyanocobalamin/Hydroxocobalamin: Cyanocobalamin nasal spray, (Nascobal, USA) is approved only for weekly maintenance therapy, a month after receiving $100 \mathrm{mcg}$ intramuscular B12. The current usage pattern of Cyanocobalamin is that all hematologic parameters should be normal when beginning treatment with Cyanocobalamin nasal spray [18].

Scientific data suggest that the relative bioavailability of the nasal formulations of cyanocobalamin and hydroxocobalamin (versus intramuscular) is $2 \%$ [19] to $6.1 \%$ [18] and $2 \%$ to $5 \%$ [20] respectively. Interestingly, authors have concluded that it was time to drop cyanocobalamin [30].

Oral Formulations: Oral vitamin B12 supplementation is considered to be less reliable. For example, a pharmacokinetic study, conducted by Castelli et al, on a "conventional" commercial oral formulation demonstrated an absolute bioavailability of only $2.16 \%$ [21].

\section{Limitations of oral therapy: $[22,23]$}

1. Poor absorption (by passive transport)

2. Unpredictable and unreliable absorption pattern

3. Not reliable for the treatment of pernicious anemia

4. Not suitable for patients with nausea, vomiting or who are unable to tolerate oral medication 
5. Concerns about swallowing difficulties

6. Non compliance due to long term daily dosing

7. Due to poor absorption, cost to benefit ratio does not favor oral therapy

Table 3: Incidence of treatment-emergent adverse events (safety population) display of adverse events ( $\mathrm{N}=103)$.

\begin{tabular}{|c|c|}
\hline $\begin{array}{l}\text { System Organ Class } \\
\text { Preferred Term }\end{array}$ & $\mathrm{n}(\%)$ \\
\hline Gastrointestinal disorders & 4 (3.9) \\
\hline Diarrhea & $2(1.9)$ \\
\hline Dyspepsia & $1(1.0)$ \\
\hline Nausea & $1(1.0)$ \\
\hline Vomiting & $1(1.0)$ \\
\hline General disorders and administration site conditions & 2 (1.9) \\
\hline Peripheral swelling & $1(1.0)$ \\
\hline Pyrexia & $1(1.0)$ \\
\hline Infections and infestations & $1(1.0)$ \\
\hline Bacterial infection & $1(1.0)$ \\
\hline Injury, poisoning and procedural complications & $2(1.9)$ \\
\hline Phlebitis & $2(1.9)$ \\
\hline Metabolism and nutrition disorders & 4 (3.9) \\
\hline Decreased appetite & $1(1.0)$ \\
\hline Iron deficiency anemia & $3(2.9)$ \\
\hline Musculoskeletal and connective tissue disorders & $1(1.0)$ \\
\hline Temporomandibular joint syndrome & $1(1.0)$ \\
\hline Nervous system disorders & 2 (1.9) \\
\hline Headache & $2(1.9)$ \\
\hline Hypoaesthesia & $1(1.0)$ \\
\hline Paraesthesia & $1(1.0)$ \\
\hline Reproductive system and breast disorders & $1(1.0)$ \\
\hline Breast pain & $1(1.0)$ \\
\hline Pelvic pain & $1(1.0)$ \\
\hline Vaginal discharge & $1(1.0)$ \\
\hline Respiratory, thoracic and mediastinal disorders & $3(2.9)$ \\
\hline Cough & $1(1.0)$ \\
\hline Nasal congestion & $1(1.0)$ \\
\hline Rhinorrhoea & $1(1.0)$ \\
\hline Skin and subcutaneous tissue disorders & $1(1.0)$ \\
\hline Pruritus & $1(1.0)$ \\
\hline
\end{tabular}

Note: Adverse events were coded using Medical Dictionary for Regulatory Activities (MedDRA) dictionary (version: 20.0) Patients having multiple events within same system organ class were counted only once in respective system organ class under any event. Patients having multiple events with same preferred term were counted only once within the respective PT. System organ class has been sorted alphabetically and preferred terms have been sorted within each system organ class alphabetically.
Sublingual Formulations: While, oral therapy may not be appropriate for those with swallowing difficulties, an alternate route of therapy for vitamin B12 deficiency is by the sublingual mucosa [24]. There is less clinical data on sublingual formulations of Vitamin B12. However, since vitamin B12 is a large molecule, which is hydrophilic, the absorption needs to be confirmed. Absorption of vitamin B12 from sublingual formulation may actually take place from the GI tract, after saliva has cleared the dose from the oral cavity. Thus oral or sublingual supplementation requires a higher dose of vitamin B12 to be administered and does not provide a predictable increase of vitamin B12 in the body.

Parenteral administration; intramuscular (IM) or intravenous (IV): IM/IV is often preferred to reliably treat vitamin B12 deficiency by clinicians. Patients with previous stomach and terminal ileum resections are often treated with IM or IV vitamin B12 injections. Usually, the patient is put on a lifetime regimen of monthly maintenance injections. From a clinical perspective, vitamin B12 injection is painful and difficult to administer to disabled or elderly patients. Besides, the patient needs to visit a health professional repeatedly, leading to inconvenience and hence, compromised compliance.

Limitations of parenteral therapy: [25-27]

1. Not ideal route for vitamin B12 supplementation in elderly due to loss of muscle mass (Sarcopenia) and they are often on anticoagulants

2. Frequent need of health professional's assistance, makes patient dependent.

3. Very inconvenient due to frequent visits to the clinics, hence promotes non-compliance.

4. Painful and long term injection lead to inconvenience and non compliance

5. Injection site related adverse reactions.

6. Allergic reactions and severe anaphylactic reactions are reported.

7. Cost of overall treatment is high.

In contrast to oral Vitamin B12 therapy, Naso B12 ${ }^{\circledast}$ is associated with rapid, consistent, predictable and reliable absorption. Naso B12 ${ }^{\circ}$ can be self- administered with high compliance, even by patients with swallowing problems, nausea or vomiting, or with absorption issues, including pernicious anemia, post-bariatric surgery and malabsorption.

In contrast to injectable vitamin B12 therapy, Naso $\mathrm{B} 12^{\oplus}$ has lower cost, lower manpower burden, does not require a patient of an accompanying person to visit a healthcare facility, is self-administered and painless, has few adverse events, and has high compliance.

NasoB $12^{\circledast}$ is the world's first Methylcobalamin nasal spray, designed and delivered keeping light-sensitivity in mind.

NasoB $12^{\infty}$ was well tolerated and associated with a rapid rise of hemoglobin.

Our data opens the door for more research on how the formulation delivery system and packaging, which protect vitamin B12 from light, would lead to clinically meaningful outcomes in the real world.

\section{Study limitations and directions for future research}

Our intention was not to study the underlying cause for low Vitamin B12 levels, but rather, to correct them, irrespective of the underlying causes. Future researchers may well study the effect on various dietary patterns and etiologic subtypes. This study excluded patients with 
neurological symptoms, pregnant and lactating women and children; hence, future studies are needed to see the effect in these patients. The subjects were followed up for six weeks; and hence, a clinical trial is being planned with a longer follow-up, comparing NasoB $12^{\circ}$ with Oral/ Injectable B12 in "Low-Normal/Sub-clinical Cobalamin deficiency" (B12 150-399 pg/ml) patients and in overtly symptomatic, clinically deficient $(\mathrm{B} 12<150 \mathrm{pg} / \mathrm{ml})$ patients.
Along with a rise in B12 levels, a hematopoietic response is important, $[28,29]$ and we observed such a response in our study. Some other publications reported the serum B12 level, but did not follow hematopoietic responses [30,31-34]. A strong point of this work concerns monitoring of hemoglobin and reticulocyte changes, but larger, population-based studies are needed to confirm this effect. We have not done the MCV, MMA and Homocysteine but

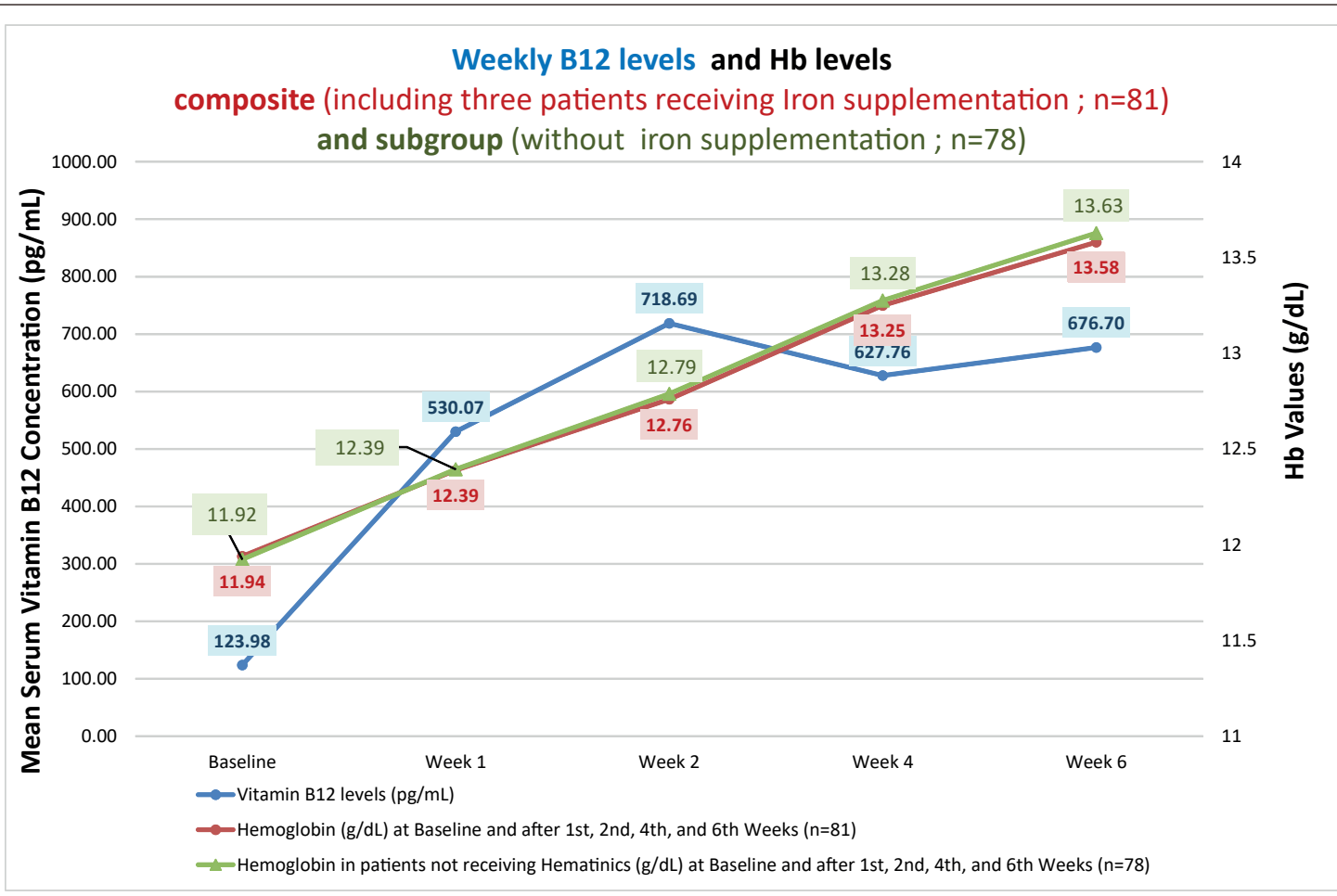

Appendix Supplementary Figure 1: Hemoglobin $(\mathrm{g} / \mathrm{dL}$ ) in all patients ("composite", $\mathrm{n}=81$ ) vs. patients who did not receive Iron supplementation ("subgroup", $\mathrm{n}=78$ ).

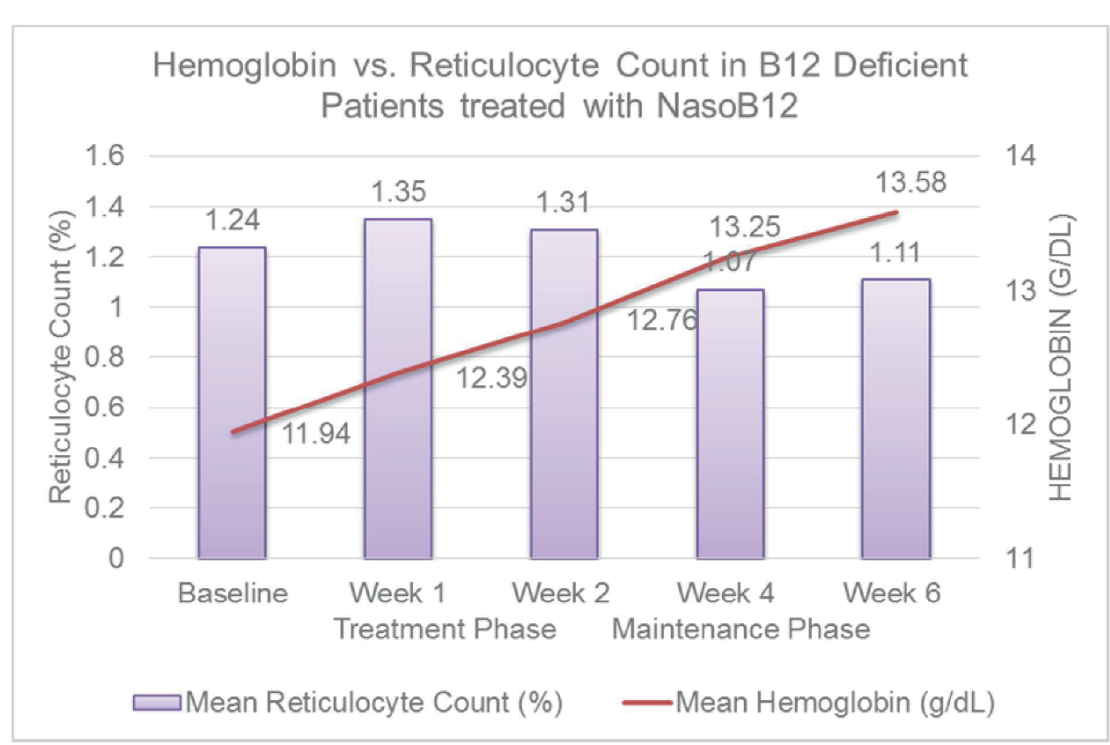

Appendix Supplementary Figure 2: Hemoglobin versus reticulocyte counts. 
in future research these parameters will be included. Given the rise of Hemoglobin with NasoB $12^{\circ}$, future studies could be designed for pernicious anemia, and also focus on the children, adolescents, women, especially pregnant women and the elderly $[29,30,35]$.

\section{Conclusion}

In the present clinical study, at the end of treatment phase, a statistically significant rapid rise in mean serum vitamin B12 levels was achieved and maintained till the end of the maintenance phase. NasoB $12^{\circ}$ was associated with a favorable hematopoietic response. Therefore, NasoB $12^{\circ}$ can be beneficial for the treatment and maintenance of serum vitamin B12 levels in patients with low serum Vitamin B12 levels. Thus, NasoB $12^{\circ}$ offers a fast and consistent alternative to oral or sublingual B12 therapy; and a simpler and convenient alternative to B12 injections, without safety concerns.

\section{Appendix}

Supplementary figures [SF1 \& SF2].

\section{Author Contributions}

Conceptualization, methodology, study conduct, formal analysis, access to all data, verification of data and interpretation: TS, VS, DB, SM, AA, PP, PC; writing-original draft preparation, TS, VS, DB, SM, AA, PP, PC, writing-review and editing, TS, VS, DB, SM, AA, PP, PC, visualization, TS, VS, DB, SM, AA, PP, PC. All authors have read and agreed to the published version of the manuscript.

\section{Funding}

This research was funded by Troikaa Pharmaceuticals Limited. Grant number INMEC-CT.

\section{Clinical Trial Registry}

CTRI No: CTRI/2015/06/005952 at www.ctri.nic.in.

\section{Acknowledgments}

We are grateful to all our patients and their care-givers.

\section{Conflicts of Interest}

The authors declare no conflict of interest. The funders had no role in the design of the study; in the collection, analyses, or interpretation of data; in the writing of the manuscript, or in the decision to publish the results.

\section{References}

1. Green R, Allen LH, Bjørke-Monsen AL, Brito A, Guéant JL, et al. (2017) Vitamin B 12 deficiency. Nat Rev Dis Primers 3: 1-20.

2. Langan RC, Goodbred AJ (2017) Vitamin B12 Deficiency: Recognition and Management. Am Fam Physician 96: 384-389.

3. Hunt A, Harrington D, Robinson S (2014) Vitamin B12 deficiency. BMJ: g5226.

4. da Silva L, McCray S (2009) Vitamin B 12: No One Should Be Without It. Practical Gastroenterol 33: 39-42.

5. https://www.ars.usda.gov/news-events/news/researchnews/2000/b12-deficiency-may-be-more-widespread-thanthought/ accessed on 28 Jan 2020.

6. Tucker KL, Rich S, Rosenberg I, Jacques P, Dallal G, et al. (2005) Plasma vitamin B-12 concentrations relate to intake source in the Framingham Offspring study. Am J Clin Nutri 71: 514-522.
7. Gramer G, Fang-Hoffmann J, Feyh P, Klinke G, Monostori P, et al. (2020) Newborn Screening for Vitamin B12 Deficiency in GermanyStrategies, Results, and Public Health Implications. J Pediatr 216: 165-172.

8. Monto RW, Rebuck JW (1994) Nasal instillation and inhalation of crystalline vitamin B12 in pernicious anemia. AMA Arch Intern Med 93: 219-230.

9. Devalia V, Hamilton MS, Molloy AM (2014) British Committee for Standards in Haematology. Guidelines for the diagnosis and treatment of cobalamin and folate disorders. Br J Haematol 166: 496-513.

10. Carmel R (2012) Subclinical cobalamin deficiency. Curr Opinion Gastroenterol 28: 151-158.

11. Rajaraman R, Bamji MS, Moitra A (2011) Micro-nutrient security for India-priorities for Research and action. Delhi: INSA (Indian National Science Academy).

12. Green R (2017) Vitamin B12 deficiency from the perspective of a practicing hematologist. Blood 129: 2603-2611.

13. Andrès E, Kurtz JE, Perrin AE, Maloisel F, Demangeat C, et al. (2001) Oral cobalamin therapy for the treatment of patients with foodcobalamin malabsorption. Am J Med 111: 126-129.

14. Van Campen CL, Riepma K, Visser FC (2019) Open trial of vitamin B12 nasal drops in adults with Myalgic Encephalomyelitis/Chronic Fatigue Syndrome: comparison of responders and non-responders. Front Pharmacol 10: 1102.

15. Slot WB, Merkus FW, Van Deventer SJ, Tytgat GN (1997) Normalization of plasma vitamin B12 concentration by intranasal hydroxocobalamin in vitamin B12-deficient patients. Gastroenterol 113: 430-433.

16. Kelly G (1997) The co-enzyme forms of vitamin B12: Toward an understanding of their therapeutic potential. Alt Med Rev 2: 459471.

17. Freeman AG (1992) Cyanocobalamin--a case for withdrawal: discussion paper. J Royal Society Med 85: 686.

18. US FDA (2020) Cyanocobalamin (Nascobal) Nasal Spray 500mcg/ spray.

19. Tillemans MP, Donders EM, Verweij SL, Van der Hoeven RT, Kalisvaart KJ (2014) Effect of administration route on the pharmacokinetics of cobalamin in elderly patients: a randomized controlled trial. Cur Ther Res 76: 21-25.

20. Van Asselt DZ, Merkus FW, Russel FG, Hoefnagels WH (1998) Nasal absorption of hydroxocobalamin in healthy elderly adults. British J Clin Pharmacol 45: 83-86.

21. Castelli MC, Wong DF, Friedman K, Riley MG (2011) Pharmacokinetics of oral cyanocobalamin formulated with sodium $\mathrm{N}$-[8-(2-hydroxybenzoyl) amino] caprylate (SNAC): an open-label, randomized, single-dose, parallel-group study in healthy male subjects. Clin ther 33: 934-945.

22. Delpre G, Stark P, Niv Y (1999) Sublingual therapy for cobalamin deficiency as an alternative to oral and parenteral cobalamin supplementation. Lancet 354: 740-741.

23. G Delpre, P Stark, Y Niv (1999) Sublingual therapy for cobalamin deficiency as an alternative to oral and parenteral cobalamin supplementation. Lancet 354: 740-741. 
24. Sharabi A, Cohen E, Sulkes J, Garty M (2003) Replacement therapy for vitamin B12 deficiency: comparison between the sublingual and oral route. Br J Clin Pharmacol 56: 635-638.

25. Turnheim K (2004) Drug therapy in the elderly. Exp Gerontol 39: 1731-1738.

26. Mühlberg W, Sieber C (2004) Sarcopenia and frailty in geriatric patients: implications for training and prevention. Z Gerontol Geriatr 37: 2-8.

27. Tillemans MP, Donders EM, Verweij SL, Van der Hoeven RT, Kalisvaart KJ (2014) Effect of administration route on the pharmacokinetics of cobalamin in elderly patients: a randomized controlled trial. Curr Ther Res Clin Exp 76: 21-25.

28. Greibe E, Nymark O, Fedosov SN, Heegaard CW, Nexo E (2018) Dietary intake of vitamin B12 is better for restoring a low B12 status than a daily high-dose vitamin pill: An experimental study in rats. Nutrient 10: 1096.

29. Naik S, Mahalle N, Greibe E, Ostenfeld MS, Heegaard CW, et al. (2019) Cyano-B12 or Whey Powder with Endogenous Hydroxo-B12 for Supplementation in B12 Deficient Lactovegetarians. Nutrients 11: 2382.
30. Anon (1984) Time to drop cyanocobalamin? Drug Ther Bull 22: 4344.

31. Keenan A, Whittam B, Rink R, Kaefer M, Misseri R, et al. (2015) Vitamin B12 deficiency in patients after enterocystoplasty. J Pediatr Urol 11: 273e1-273e5.

32. Singh C, Kawatra R, Gupta J, Awasthi V, Dungana H (2016) Therapeutic role of Vitamin B12 in patients of chronic tinnitus: A pilot study. Noise Health 18: 93.

33. van Walraven CG, Naylor CD (1999) Use of vitamin B12 injections among elderly patients by primary care practitioners in Ontario. CMAJ 161: 146-149.

34. Saraswathy AR, Dutta A, Simon EG, Chacko A (2012) Sa1100 Randomized Open Label Trial Comparing Efficacy of Oral Versus Intramuscular Vitamin B12 Supplementation for Treatment of Vitamin B12 Deficiency. Gastroenterol 142: S-216.

35. Hovding G (1968) Anaphylactic reaction after injection of vitamin B12. Br Med J 3: 102. 